It was observed by Churchman ${ }^{23}$ in some classical studies on the sensitivity of more than a hundred bacterial species to the growth-inhibitory action of Gentian Violet (Crystal Violet and lower homologues) that there was a 90 per cent correlation between sensitivity of growth to the dye and staining with it by the Gram technique. The Neisseria and $\mathrm{Cl}$. welchii and $C l$. sporogenes were among the main exceptions. There is consequently a complete correlation between sensitivity to Gentian Violet and the presence of the phosphoric ester $X \boldsymbol{P}$ in the small group of organisms which we have studied.

The good correlation between the penicillin sensitivity and $X P$ content shown by the data of the table led to a study of the natural variation of the $X P$ content of a culture of Mic. pyogenes var. aureus during growth and the effect of penicillin on the course of the variation. In the normal culture, the $X P$ content expressed as micromoles of phosphate per gram dry weight was about 300 at the beginning of growth, fell to about 150 during the logarithmic phase and rose again to a resting value of about 300 in the stationary phase. The addition of $1 \mu \mathrm{gm} . / \mathrm{ml}$. ( $50 \mathrm{\mu gm} . / \mathrm{mgm}$. cell dry weight) of penicillin $\mathrm{G}$ to the culture in the late log phase caused the total amount of the phosphoric ester $X P$ in the culture to decrease almost linearly to about one-half in the space of one mean generation-time, although during this period slow growth of the culture continued. When growth ceased, the $X P$ content of the cells had fallen to less than 50 micromoles of phosphate per gram.

The only biochemical change which has been reported to be initiated immediately after the initial attachment of penicillin to growing cells is the increase in the free nucleotide content ${ }^{24}$. It is evident that the $X P$ content begins to decrease also promptly after the initial attachment of penicillin. The synthesis of $X P$ is prevented; but its utilization and breakdown is not prevented by the action of the penicillin.

Experiments with disintegrated cells have shown that the phosphoric ester $X P$ is attached to the cell envelopes. The presence of this ester in the cell envelopes suggests that the inhibition of its production by penicillin may be connected with the disturbance of cell wall expansion in penicillin-treated cells ${ }^{25}$ and with the impairment of function of the osmotic barrier ${ }^{26}$ and of the transfer systems located therein 27 .

We have been able to confirm the observations of Gutstein $^{12}$ and Schumacher ${ }^{6}$ that certain microorganisms do not become Gram-negative after most of the nucleic acid (more than 90 per cent of the ribonucleic acid) is extracted. But it was found that the Gram staining of the cells afterwards diminished as the $X P$ was removed by prolonged extraction. In the same way, the intensity of the Gram staining of cells growing in the presence of penicillin has been found to follow their $X P$ content. We are consequently inclined to accept Gutstein's view of the arrangement of the components of the cortical layer of Gram-positive bacteria and to consider that the phosphoric ester $X P$ represents part of the acidic cortical component which he described ${ }^{12}$.

In our experience there is no correlation between ribonucleic acid content and Gram staining; but such a correlation might erroneously be observed if $X P$ phosphorus were mistaken for ribonucleic acid phosphorus: We consequently find it difficult to accept the view ${ }^{10}$ that the essential component of the so-called Gram complex is magnesium ribonucleate.
It seems, however, that there is a strong correlation between the Gram-staining reaction and the presence of the acidic component $X P$. This makes possible the chemical recognition of Gram-positive organisms on a quantitative scale. The correlation of the $X P$ content and the capacity of organisms for retaining Gram's stain involves also a correlation with the other characteristics of Gram-positive organisms, their susceptibility to lytic agents, their autolysis and enzymic degradation, their capacity for accumulating amino-acids, the physiological effects of Crystal Violet, penicillin and other substances selectively active upon this group.

It is hoped that the work now in progress in our laboratory on the origin and nature of the $X P$ fragment and the relationship of it to physiological function will throw light on its physico-chemical relationship to the known characteristics of Grampositive organisms.

We are indebted to the Medical Research Council for the receipt of grants which are financing this work.

${ }^{1}$ Gram, H. C. J., Fortschr. Med., 2, 185 (1884).

${ }^{2}$ Pelet, G. C., Chem. Zent., 1259 (1907, I).

${ }^{3}$ Benians, T. H. C., J. Path and Bact., 23, 401 (1919-20). Burke, V., and Barnes, M. W., J. Bact., 18, 69 (1929). Kemp, H. A., Stain Tech., 6, 53 (1931).

- Schumacher, J., Z. Bakt., Abt. I Orig., 98, 104 (1926).

${ }^{5}$ Deussen, E., Z. Hyf. InfektKr., 85, 234 (1918); 93, 512 (1921).

- Schumacher, J., Z. Bakt., Abt. I Orig., 109, 181 (1928).

${ }^{7}$ Dreyer, G., Scott, S. G., and Walker, E. W. A., J. Path and Bact., 15, 134 (1911).

${ }^{8}$ Stearn, E. W. and Stearn, A. E., J. Bact., 9, 463 and 479 (1924); 10, 13 (1925) ; Protoplasma, 12, 435 (1931).

- Dubos, R. J., J. Exp. Med., 65, 873 (1937). Thompson, R. H. S., and Dubos, R. J., J. Biol. Chem., 125, 65 (1938).

${ }^{10}$ Henry, H., and Stacey, M., Nature, 151, 671 (1943). Henry, H., Stacey, M., and Teece, E. G., Nature, 156, 720 (1945). Henry, Stearn, A. E., J. Bact., 19, 133 (1930).

${ }^{12}$ Gutstein, M., Z. Bakt., Abt. I Orig., 95, 1 (1925).

${ }^{13}$ Kantorowicz, A., Münch. med. Wehsehr., 56, 897 (1909).

${ }^{14}$ Kruse, Munch. med. Wchschr., 57, 685 (1910).

${ }^{16}$ Smith, H. W., Amer. J. Hyg., 2, 607 (1922). 16 Bartholomew, J. W., and Umbreit, W. W., J. Bact., 47, 415 (1944);
48,567 (1944).

${ }_{17}$ Jobling, J. W., and Petersen, W., J. Exp. Med., 20, 456 (1914).

${ }_{18}$ Stacey, M., Symposia of Soc. Exp. Biol., 1, 86 (1947), see p. 99.

19 Webb, M., J. Gen. Microbiol., 2, 260 (1948).

${ }^{0}$ Schmidt, G., and Thannhauser, S. J., J. Biol. Chem., 161, 83 (1945).

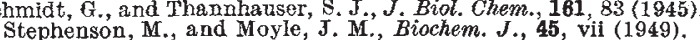

${ }^{21}$ Mitchell, P., J. Gen. Microbiol. (in the press).

${ }^{22}$ Verhoff, F. H., J. Amer. Med. Assoc., 115, 1545 (1946).

${ }^{23}$ Churchman, J. W., J. Exp. Med., 16, 221 (1912).

${ }^{24}$ Mitchell, P., Nature, 164, 259 (1949).

${ }^{25}$ Gardner, A. D., Nature, 146, 837 (1940).

${ }^{26}$ Mitchell, P., Symposium of Soc. Gen. Microbiol. on the Nature of the Bacterial Surface, 55 (1949).

${ }^{27}$ Gale, E. F., and Taylor, E. S., J. Gen. Microbiol., 1, 314 (1947).

\section{LONG ASHTON RESEARCH STATION}

A 'FIELD day' was held at the Long Ashton A Research Station on July II, on the occasion of the annual meeting of members of the National Fruit and Cider Institute. Visitors were conducted around the plantations, where they saw field trials, including particularly those dealing with the manuring of blackcurrants and strawberries, mineral deficiencies of apples and potatoes, and systems of culture and management of apples and pears; machinery for pest and disease control, designed at Long Ashton, was demonstrated. In the Cider House an exhibit of fruit, photographs and charts provided information about the varieties of cider apples recommended for 
planting, while another section dealt with the manufacture of apple juice.

In the laboratories were various exhibits which perhaps appealed more to the research worker, as they showed the work now in progress in the investigation of fundamental problems.

Sand culture. The plant nutrition sand culture section included the demonstration of equipment needed to study micro nutrient deficiencies in crops on a large scale. The automatic apparatus used to purify several tons of sand for this work was exhibited. This is designed to circulate several hundred pounds of sand at one time in contact with mineral acid or other extracting reagents. Steam issuing under pressure from a special jet assembly is used to transport and heat the sand and acid. The steam is generated in a $30 \mathrm{~kW}$. automatic electrode boiler. The equipment is housed in a building with forced ventilation and neutralizing pits for waste acid. Sand treated in the apparatus is practically devoid of available micro nutrients and contains as little as $10^{-5}$ p.p.m. molybdenum. Several 'Pyrex' glass continuous distillation units and synthetic ionexchange resins provide an adequate pure water supply.

Experimental work in progress in the sand culture section includes studies on molybdenum nutrition of Brassicce in relation to nitrogen supply; nutrient balance experiments with potato ; relation of heavymetal toxicity to iron nutrition of sugar beet; elucidation of factors in soil acidity and the accumulation of micro nutrients by crop plants. The work on potatoes demonstrated the complexity of nutrient interrelationships ; for example, iron, potassium and phosphorus levels are critical factors in the appearance of deficiencies of each of these elements and of calcium; low potassium accentuates iron deficiency and low phosphorus diminishes chlorosis; iron supply modifies the translocation of potassium and the availability of phosphorus.

Rapid chemical tissue tests. In another laboratory rapid chemical tests for the diagnosis of the mineral status of crop plants were demonstrated. In diffusion methods the easily soluble nutrients are extracted from predetermined portions of fresh plant material, using an acetate buffer solution. Tests for potassium, magnesium, calcium, phosphorus, nitrate nitrogen, and manganese at normal and deficiency levels are made on suitable aliquots of the extracts. Toxicity levels of chlorine, manganese and aluminium can also be determined. In maceration methods Waring and N.I.R.D. blenders are used for the extraction of nutrients from fresh plant tissues. A special carbon, 'Darco G 60', is used to clarify the tissue extract. The nutrient levels roughly parallel those obtained by the diffusion method, but are at a higher level.

'Pyrex' glass macerators are used to extract the micronutrients, namely, iron, copper, zinc, lead, nickel, cobalt, etc., from fresh plant material, and special chemical methods are used for their detection. The method is in use to study aspects of the effects of heavy metals on iron metabolism in economic crops. The chemical tissue test data are related to manurial treatment, final yields of crops, and ash analysis of the plants. The methods are valuable aids for a quick diagnosis of a mineral disorder in crop plants.

Radioactive phosphorus. Radioactive phosphorus $\left(\mathbf{P}^{32}\right)$ is being used to 'tag' phosphatic fertilizers in nutrition experiments on fruit trees and in other investigations on the effect of grass cover-crops in orchards. It is also being used to follow the course of systemic insecticides in plants. Up to the present time, much of the work at Long Ashton has been designed to determine the amount of phosphorus-32 which can be used without invalidating experimental results by radiation injury to the plants. The technique employed, including the use of the Geiger counter and other apparatus, was demonstrated.

Aspergillus niger as a test organism for mineral nutrients. Another exhibit showed the method of using Aspergillus niger (Mulder's $M$ strain) as a test organism to determine magnesium, copper, zinc and molybdenum available in soils to crop plants. If any essential mineral element is omitted from a basal culture solution containing all others at satisfactory levels, the growth of the fungus, as judged by dry weight and sporulation, is markedly reduced. The response to the addition of this element in various amounts is specific and quantitative; thus a growth series can be prepared for any essential element, which is assessed by intensity and colour of spore cover and dry weight of mycelium. Test materials of soils, tissue extracts or ash of plants are placed in basal solutions containing all the mineral elements other than the one to be determined, and the growth of the fungus under these conditions depends on the amount of nutrient it obtains from the material added. The application of this method to soil problems has shown magnesium deficiency in the presence of potassium shortage, copper deficiency in certain alkaline fen soils where cereal crops were affected and in sandy soils where fruit trees showed 'dieback' symptoms, zine deficiency in a sandy soil where apples and pears suffer from 'Iittle leaf', and molybdenum deficiency in acid soils where Brassica crops showed 'whiptail' symptoms.

Plant hormones. Three different methods in use at Long Ashton for the biological estimation of plantgrowth substances were demonstrated. (1) A modified form of the Avena coleoptile cylinder test in which the growth of coleoptile sections floating on the surface of the test solution is measured. (2) The Coleus leaf abscission test. Excised portions of Coleus nodes, each with an attached petiolar base, are mounted on damp filter paper. The cut end of the petiole is then covered with a small disk of filter paper impregnated with the test solution, and the time taken for the abscission layer to develop is noted. (3) The tomato ovary test. In this test unpollinated tomato ovaries are treated with known volumes of test solution and the rate of growth of the young fruitlets is measured over a period of six days. The growth is compared with that induced by known amounts of 2-naphthoxyacetic acid.

By means of charts and diagrams, it was shown how these tests are being used to study various pomological problems, in particular the cause and control of fruit-drop in apples and pears, and the winter dormancy of buds of fruit trees.

Systemic insecticides. This exhibit showed the residual toxicity of apple seedlings to Aphis pomi produced by application to the soil of bis( $\beta$-fluorosthoxy)methane, $\mathrm{CH}_{2}\left(\mathrm{OCH}_{2} \mathrm{CH}_{2} \mathrm{~F}\right)_{2}$, bis (dimethylamino)fluorophosphine oxide, $\left[\left(\mathrm{CH}_{3}\right)_{2} \mathrm{~N}\right]_{2} \mathrm{POF}$ and bis (dimethylamino) phosphonous anhydride, $\left[\left(\mathrm{CH}_{3}\right)_{2} \mathrm{~N}\right]_{2}$ P.O.O.PO $\left[\mathrm{N}\left(\mathrm{CH}_{3}\right)_{2}\right]_{2}$, at amounts ranging from 500 to 25 p.p.m. of soil. The phytotoxicity of the materials on apple seedlings and their effect on growth was also demonstrated. 
Photographs were used to show the residual toxicity of the above materials to $A$. pomi when applied in aqueous solution to the leaves of apple seedlings.

Virus diseases of tree fruits. Little is known of the actual extent of virus diseases of fruit trees in Britain, but virus-like symptoms are commonly seen in orchards; a number of specimens showing leaf symptoms probably caused by virus infection were shown, including mosaics, ring-spots, linepatterns, and necrotic spots. In addition to leaf symptoms, virus infection can cause changes in growth habit; this type of symptom was illustrated by rubbery wood of apple and stunt of plum. In rubbery apple, lignification of the wood is irregular and delayed, with the result that the young branches are flexible and soft and the tree has a 'weeping' habit of growth ; in stunted plum the wood in the shoots is very poorly developed, while the tissues outside the wood are thick and spongy, and as a result the shoots are very brittle. In both diseases the inter. nodes are shortened. Neither of these diseases causes leaf symptoms on the host on which they were first recorded, but plum stunt causes a faint mosaic on the cherry root-stock $F .12 / 1$, an example of which was shown.

G. T. SPINKS

\section{ELECTRONIC INSTRUMENTS AND DEVICES}

$\mathrm{A}^{\mathrm{T}}$

$T$ first sight, the exhibition of the Institution of - Electronics (N.W. Branch), held at Manchester during July 19-21, was perhaps a little disappointing after last year's brilliant display ; but a closer inspection revealed that, although there were fewer spectacular demonstrations, a remarkable number of new, ingenious and useful devices were on show. Since it is obviously impossible to mention them all in the space allowed, a few of the most novel and interesting exhibits will be described.

An outstanding feature of the exhibition was the substitution of television demonstrations for the usual film shows. The receivers used were all built by members of the Institution, either from a commercial kit of parts or from government surplus equipment, and a short lantern lecture on the elementary principles of television preceded each demonstration.

Among the high-vacuum equipment displayed by British American Research, Ltd., was a new type of gauge known as the 'Alphatron', which has a linear response from 1 micron to $10 \mathrm{~mm}$. of mercury. It is an ionization gauge in which a small quantity of radium provides a constant source of alpha-particles as the ionizing agent, and is consequently more robust and stable than the conventional type which uses electrons emitted from a heated filament.

Dawe Instruments, Ltd., displayed a stroboscope specially designed for viewing the moving shuttle of a textile loom. It uses an extremely high-intensity flash which gives a clear view of a moving object at very low repetition-rates, and a remote phase-control enables the operator to view the shuttle at any position during its traverse. The same firm also demonstrated its sound-level meter, which has been completely redesigned and now, while retaining the features of the earlier model, has its size and weight reduced by approximately one-half.

A high-voltage insulation tester which gives aural warning of the approach of a breakdown was dis- played by the English Electric Co., Ltd. A continuously variable D.C. potential of up to $10 \mathrm{kV}$. is derived by rectification of the output of an air-cored transformer which is fed by a high-frequency valve oscillator. The A.c. components of the ionization current which precedes breakdown are amplified and fed to a small loudspeaker. The instrument is portable and, since the maximum current obtainable is $0.5 \mathrm{~mA}$., it is completely safe. Among other equipment demonstrated by this firm were a $5-\mathrm{kW}$. induction heater designed as a general production tool rather than for specialized work, and a stepless controller for $\frac{1}{2}$ h.p. D.c. motors using a magnetic amplifier and metal rectifiers.

Interesting demonstrations of the phenomenon of electron diffraction were provided by Ferranti, Ltd. Cathode ray tubes are used in which a specimen of crystalline material is supported in the beam and the diffraction pattern observed on the screen. This firm also has available a continuously pumped tube in which specimens can be changed at will.

The equipment displayed and demonstrated by Fielden (Electronics), Ltd., was an excellent example of the way in which one or two basic instruments can be made to serve a large number of specialized purposes. In particular, the proximity meter, displayed in its basic form at last year's exhibition, and which depends on the measurement of very small capacity changes, has been made the basis of a bewildering variety of new instruments. Perhaps the most interesting application is in a new type of recorder which has the sensitivity of a high-grade pointer galvanometer but sufficient power to operate a substantial pen. A servo mechanism combined with the proximity device causes the pen to follow the pointer by maintaining a constant capacity between light vanes fixed to each. There is thus no mechanical contact between the meter and the recording mechanism. A similar principle is involved in an instrument for recording changes in level of a liquid as in a manometer or thermometer. Other applications which were illustrated involved counters, tolerance gauges, moisture indicators and a recording hygrometer.

A new standard 'signal generator by Marconi Instruments, Ltd., provides a continuously variable output from 0.4 micro-volts to 4 volts in the frequency range $15 \mathrm{kc} . / \mathrm{s} .-30 \mathrm{Mc} . / \mathrm{s}$. Several unusual features are incorporated: a crystal-controlled oscillator for calibration checking and a novel form of concentric terminating unit are of special interest. The latter provides three output conditions-source impedances of $75 \mathrm{ohms}$ and $30 \mathrm{ohms}$ and a dummy aerial-and the fundamental circuit of each is indicated by a line diagram which changes as the switch is changed.

Metropolitan-Vickers Electrical Co., Ltd., displayed the precision wave-guide test gear for the $3-\mathrm{cm}$. band which has been developed in conjunction with the Telecommunications Research Establishment of the Ministry of Supply. Its own centimetre-wave signal source, which is of extremely small dimensions, was also on show. The latter provides a signal, tunable between 8,500 and $9,700 \mathrm{Mc}$./s., from a $723 \mathrm{~A} / B$ reflex klystron with a built-in wavemeter and attenuator.

The new audio-frequency wave analyser displayed by Muirhead and Co., Ltd., has been produced in collaboration with the Pametrada Research Station, Wallsend. It is designed primarily to assist the investigation of noise and vibration in marine tur- 